K. Szymlek

Centrum Techniki Okrętowej S.A., Zakład Badawczo - Rozwojowy, Ośrodek Materiałoznawstwa, Korozji i Ochrony Środowiska, Al. Rzeczypospolitej 8, 80-369 Gdańsk

\title{
SPAWANIE ELEKTRONOWE I SPAWANIE TIG BLACH Z TYTANU TECHNICZNEGO
}

\begin{abstract}
STRESZCZENIE
W artykule przedstawiono badania metalograficzne, próby rozciagania i pomiary twardości złączy spawanych z tytanu technicznego Grade 2. Złącza spawane zostały wykonane za pomocą spawania elektronowego i za pomocą spawania TIG.
\end{abstract}

Stowa kluczowe: spawanie elektronowe, spawanie TIG, badania metalograficzne, tytan

\section{WSTĘP}

Tytan i jego stopy charakteryzują się wysoką wytrzymałością przy stosunkowo niskim ciężarze właściwym oraz wysoką odpornością na korozję w powietrzu, w wodzie morskiej i wielu środowiskach korozyjnych. Ze względu na swoje cechy tytan stosowany jest $\mathrm{w}$ przemyśle chemicznym, lotniczym, energetyce jądrowej i $\mathrm{w}$ przemyśle obronnym [1-4].

$\mathrm{Z}$ zastosowaniem tytanu na różne konstrukcje wiąże się opanowanie technologii spawania. Jedną z metod spawania tytanu jest spawanie TIG, jednak ze względu na zbyt małą wydajność tej metody poszukuje się innych bardziej wydajnych wyników (np. spawanie elektronowe czy laserowe). Celem tego artykułu jest przedstawienie badań metalograficznych, prób rozciagania i pomiarów twardości złączy spawanych wykonanych za pomocą metody TIG i spawania elektronowego.

\section{METODYKA BADAŃ}

Do badań zastosowano blachę o grubości $2 \mathrm{~mm}$ z tytanu technicznego Grade 2. Skład chemiczny blachy przedstawiono $\mathrm{w}$ tabl. 1. Analizę kontrolną składu chemicznego przeprowadzono na spektrometrze iskrowym firmy ARL 3460 w Politechnice Rzeszowskiej. Własności mechaniczne badanej blachy przedstawiono w tabl. 2. Próbę statycznego rozciagania przeprowadzono na maszynie wytrzymałościowej EU-40 i na 
maszynie wytrzymałościowej MTS 810.12. Do badań zastosowano próbki płaskie zgodnie z normą PN-EN 10002-1:2004 [5].

Tablica 1. Skład chemiczny tytanu technicznego Grade 2

\begin{tabular}{|l|c|c|c|c|c|c|}
\hline \multirow{2}{*}{ Tytan Grade 2 } & \multicolumn{7}{|c|}{ Skład chemiczny, \% masy } \\
\cline { 2 - 7 } & $\mathrm{C}$ & $\mathrm{Fe}$ & $\mathrm{N}$ & $\mathrm{H}_{2}$ & $\mathrm{O}_{2}$ & $\mathrm{Ti}$ \\
\hline \multirow{2}{*}{ Norma ASTM-B-265 } & $\max$ & $\max$ & $\max$ & $\max$ & $\max$ & \\
\hline Atest 171207R & 0,080 & 0,30 & 0,030 & 0,015 & 0,250 & 99,34 \\
\hline \multirow{2}{*}{ Analiza kontrolna } & 0,026 & 0,094 & - & - & - & 99,85 \\
\hline
\end{tabular}

Tablica 2. Własności mechaniczne tytanu technicznego Grade 2

\begin{tabular}{|c|c|c|c|c|}
\hline $\begin{array}{c}\text { Tytan } \\
\text { Grade 2 }\end{array}$ & $\begin{array}{c}\mathrm{R}_{\mathrm{p} 0,2} \\
{[\mathrm{MPa}]}\end{array}$ & $\begin{array}{c}\mathrm{R}_{\mathrm{m}} \\
{[\mathrm{MPa}]}\end{array}$ & $\begin{array}{c}\mathrm{A}_{50} \\
{[\%]}\end{array}$ & $\begin{array}{c}\mathrm{Z} \\
{[\%]}\end{array}$ \\
\hline Norma ASTM-B-265 & $\min$ & $\min$ & & - \\
\hline Atest 171207R & 437 & 345 & 20 & - \\
\hline Badania własne & 453 & 530 & 26 & 45 \\
\hline
\end{tabular}

Próby spawania tytanu za pomocą metody TIG przeprowadzono na stanowisku zrobotyzowanym w firmie AIC S.A. W celu określenia optymalnych parametrów spawania wykonano dwa złącza o wymiarach $2 \times 110 \times 250 \mathrm{~mm}$ bez materiału dodatkowego.

Próby łączenia tytanu za pomocą spawania elektronowego przeprowadzono w Przemysłowym Instytucie Elektroniki w Warszawie na spawarce elektronowej WS $15 / 80$. W celu określenia optymalnych parametrów spawania wykonano 14 złączy spawanych o wymiarach 2x60x100 mm.

Przy zastosowaniu wybranych parametrów spawania wykonano po dwa próbne złącza spawane za pomoca metody TIG (oznaczone TIG 3-3 i TIG 4-4) oraz za pomocą spawania elektronowego (oznaczone jako ELE 1-1 i ELE 2-2). Złącza te posiadały wymiary $2 \times 240 \times 255 \mathrm{~mm}$. Na złączach spawanych przeprowadzono badania wizualne, radiograficzne, metalograficzne, próby rozciagania oraz pomiary twardości.

\section{WYNIKI I DYSKUSJA}

Wstępne złącze spawane za pomocą metody TIG wykonano z zastosowaniem natężenia prądu I= $93 \mathrm{~A}$, prędkości spawania $12 \mathrm{~cm} / \mathrm{min}$, wydatku gazu (argonu) od strony lica $15 \mathrm{l} / \mathrm{min}$ i od strony grani $10 \mathrm{l} / \mathrm{min}$. Powierzchnia lica otrzymanego złącza spawanego posiadała kolor niebieski i ciemnobrązowy świadczący o utlenieniu spoiny w wyniku niedostatecznej ochrony przed dostępem powietrza. Grań wykonanego złącza była 
chroniona prawidłowo, o czym świadczy srebrny kolor spoiny. Na podstawie badań wizualnych stwierdzono, że złącze spawane posiadało bardzo szeroką spoinę (szerokość lica i grani $10 \mathrm{~mm}$ ) i strefę wpływu ciepła. Łączna szerokość spoiny wraz z SWC wynosiła $30 \mathrm{~mm}$.

Kolejne złącze spawano przy zastosowaniu natężenia prądu I=130 A, napięcia $\mathrm{U}=12 \mathrm{~V}$, prędkości spawania $30 \mathrm{~cm} / \mathrm{min}$, wydatku gazu od strony lica i grani $18 \mathrm{l} / \mathrm{min}$. Do ochrony przed powietrzem od strony grani zastosowano specjalną konstrukcje skrzynkową, natomiast od strony lica zastosowano dyszę o średnicy $\phi 20 \mathrm{~mm}$. Zarówno grań jak i lico po spawaniu miało kolor srebrny. Zastosowanie zmienionych parametrów spawania spowodowało zmniejszenie szerokości spoiny (szerokość lica $8 \mathrm{~mm}$ i grani 5 $\mathrm{mm}$ ). Stosując wyżej określone parametry wykonano dwa złącza spawane oznaczone TIG 3-3 i TIG 4-4.

Dla spawania elektronowego wybrano optymalne parametry i wykonano dwa złącza o oznaczeniach ELE 1-1 i ELE 2-2. Złącze ELE 1-1 wykonano z zastosowaniem parametrów: napięcie anodowe $\mathrm{U}_{\mathrm{a}}=70 \mathrm{kV}$, prąd wiązki $\mathrm{I}_{\mathrm{a}}=8,6 \mathrm{~mA}$, prąd ogniskowania $\mathrm{I}_{\mathrm{o}}=13,8 \mathrm{~A}$, prędkość spawania $\mathrm{V}_{\mathrm{s}}=90 \mathrm{~cm} / \mathrm{min}$. Tak wykonane złącze charakteryzowało się nierównomierną szerokością spoiny na jednej trzeciej długości. Podczas wykonywania złącza ELE 2-2 zastosowano prąd wiązki o wartości $\mathrm{I}_{\mathrm{a}}=8,3 \mathrm{~mA}$, przy zachowaniu pozostałych parametrów, co zapewniło jednakową szerokość spoiny na jej całej długości.

Złącze wykonane z zastosowaniem powyższych parametrów posiadało szerokość lica ok. 1,41 mm i szerokość grani ok. 0,90 mm.

Badania radiograficzne złączy ELE 1-1, ELE 2-2, TIG 3-3 i TIG 4-4 przeprowadzono w Politechnice Gdańskiej w Katedrze Technologii Materiałów Maszynowych i Spawalnictwa. Do badań zastosowano aparat rentgenowski ANDREX 3002. Na radiogramach zaobserwowano, że złącza spawane ELE 1-1, ELE 2-2 wykazują wklęśnięcia lica i podtopienia w grani, natomiast złącza TIG 3-3 i TIG 4-4 zawieraja drobne pęcherze gazowe.

Badania mikroskopowe przeprowadzono na mikroskopie optycznym NEOPHOT 32 zgodnie z normą PN-EN 1321:2000 [6]. Na podstawie badań metalograficznych stwierdzono, że w poszczególnych strefach złącza spawanego wykonanego metodą TIG występują składniki strukturalne:

a) spoina - faza $\alpha$ ' (struktura iglasta) i faza $\alpha$ (struktura ziarnista) (rys. 1a),

b) strefa wpływu ciepła - faza $\alpha$ i faza $\alpha$ (rys. 1b). Wielkość ziaren zwiększa się w kierunku osi spoiny,

c) drobne ziarna fazy $\alpha$ materiału rodzimego (rys. 1c).

Badania metalograficzne mikroskopowe złączy spawanych elektronowo wykazały, że można wyróżnić również trzy strefy na przekroju poprzecznym złącza (rys. 2). Są to:

- spoina - składającą się z fazy $\alpha$ ' i z obszarów gruboziarnistych wysepek fazy $\alpha$ (rys. 2)

- strefa wpływu ciepła - składająca się z gruboziarnistych płytek fazy $\alpha$ (rys. 2)

- materiał rodzimy - drobnoziarnista struktura fazy $\alpha$ (rys. 2)

Na podstawie badań makro i mikrostruktury można stwierdzić, że złącza wykonane metodą TIG różnią się od złączy spawanych elektronowo następującymi cechami:

- znacznie szersza spoina i strefa wpływu ciepła,

- większe ziarna fazy $\alpha$ w strefie wpływu ciepła i w spoinie,

- w strefie wpływu ciepła struktura iglasta (faza $\alpha$ '),

- w spoinie znacznie większe rozmiary struktury iglastej. 
Próbę statycznego rozciągania złączy spawanych przeprowadzono na próbkach płaskich zgodnie z norma PN-EN 895:1997 [7] i PN-EN 10002-1:2004 [5] wraz z pomiarami wydłużenia na odcinku o długości $50 \mathrm{~mm}$. Wyniki próby statycznego rozciągania przedstawiono $\mathrm{w}$ tabl. 3 .

a)

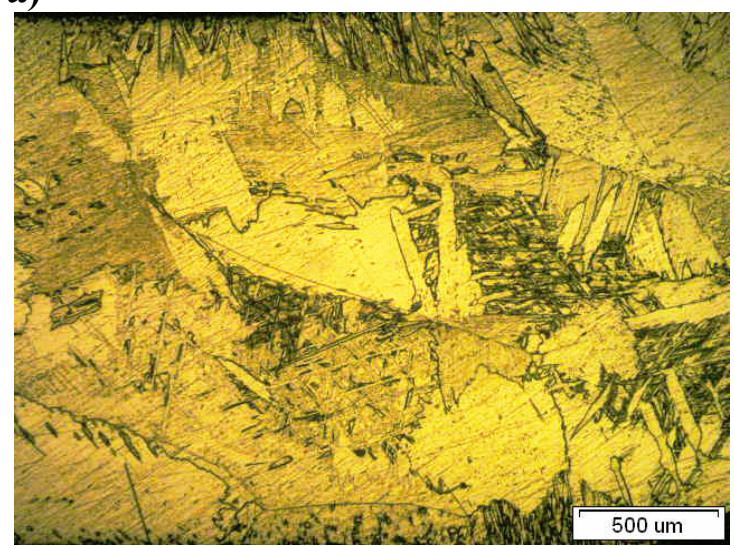

b)

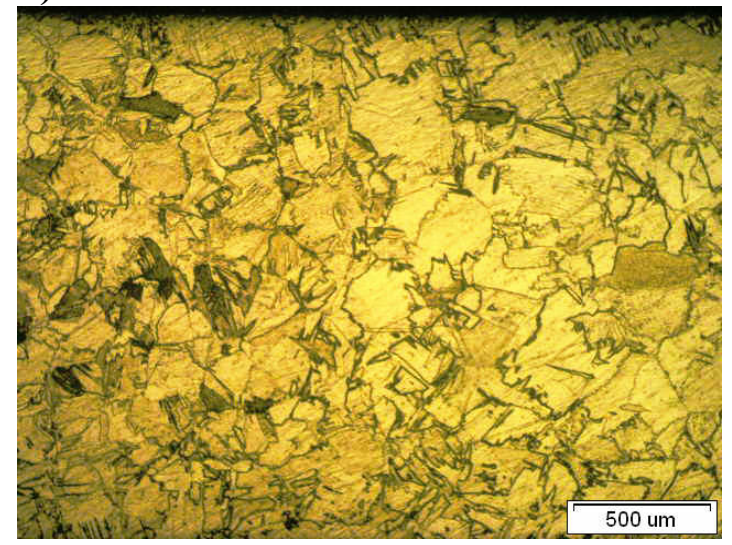

c)

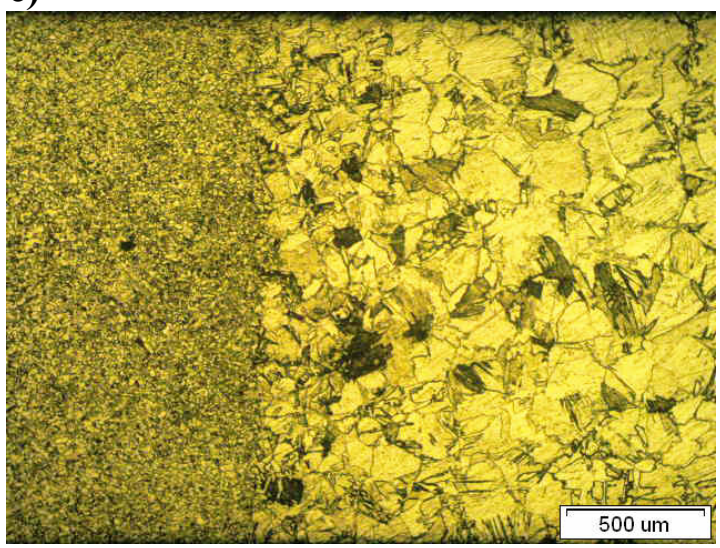

Rys. 1. Złącze spawane metodą TIG: a) spoina, b) SWC znajdująca się w pobliżu spoiny, c) z lewej strony zdjęcia widoczny jest materiał rodzimy i następnie rozrośnięte ziarna SWC

a)

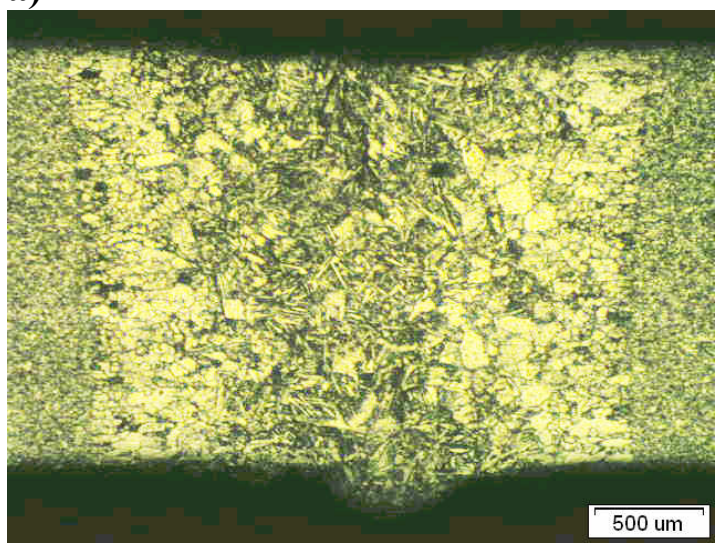

b)

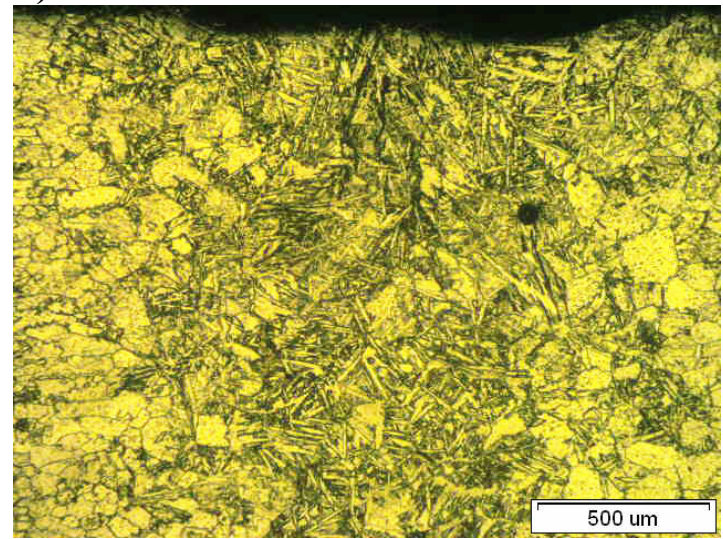

Rys. 2. Złącze spawane elektronowo: a) przekrój poprzeczny b) złącze spawane elektronowo od strony 
Tablica 3. Wyniki próby statycznego rozciągania złączy spawanych

\begin{tabular}{|c|c|c|c|}
\hline Rodzaj & $\begin{array}{c}\text { Średnia wytrzymałość na } \\
\text { rozciaganie } \\
\mathrm{R}_{\mathrm{m} \text { śr }}\end{array}$ & $\begin{array}{c}\text { Średnie } \\
\text { wydłużenie } \\
\mathrm{A}_{50 \text { śr }}\end{array}$ & $\begin{array}{c}\text { Miejsce } \\
\text { pęknięcia }\end{array}$ \\
& {$[\mathrm{MPa}]$} & 22,0 & $\begin{array}{c}\text { Materiał } \\
\text { rodzimy }\end{array}$ \\
\hline Elektronowe & 514 & 10,5 & Spoina \\
\hline TIG & 486 & &
\end{tabular}

Złącza spawane metodą TIG pękały w spoinie, co nie jest skutkiem pożądanym (poprawnym). Wydaje się, że przyczyną jest występowanie struktury iglastej (faza $\alpha^{\prime}$ ) i bardzo dużych ziaren fazy $\alpha$.

Próbki spawane elektronowo podczas próby statycznego rozciagania pękały w materiale rodzimym, co świadczy o poprawności wykonania złącza spawanego pod względem własności wytrzymałościowych.

Pomiary twardości złączy spawanych przeprowadzono zgodnie z normą PN-EN 1043-1: 2000 [8] na twardościomierzu HPO-10.

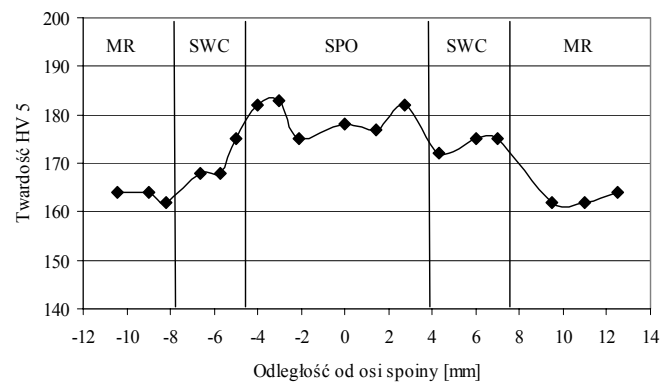

Rys. 3. Twardość HV 5 złącza spawanego metodą TIG: MR -materiał rodzimy, SWC - strefa wpływu ciepła, SPO - spoina

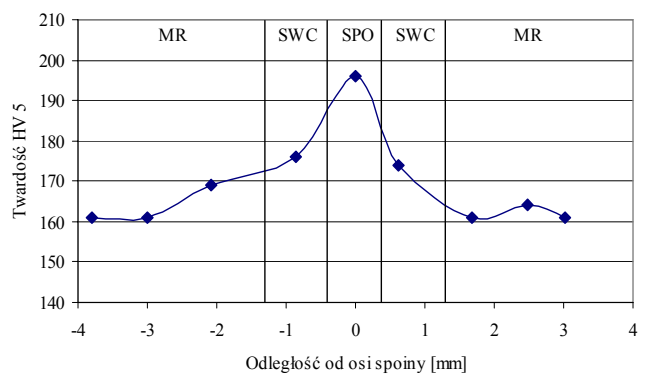

Rys. 4. Twardość HV 5 złącza spawanego elektronowo: MR -materiał rodzimy, SWC - strefa wpływu ciepła, SPO - spoina

Największą twardość w złączach spawanych metodą TIG i elektronowo wykazuje spoina. Twardość spoiny w złączu spawanym elektronowo osiagnęła wartość 196 HV 5. Stosunkowo wysoka twardość spoiny w tym złączu spowodowana jest występowaniem drobnoiglastej fazy $\alpha$ '. Twardość spoiny w złączu spawanym metodą TIG posiada wartość od 175 do $182 \mathrm{HV}$ 5. W obu złączach spawanych SWC charakteryzuje się niższą twardością od spoiny ponieważ zawiera mniejszą ilość struktury iglastej (faza $\left.\alpha^{\prime}\right)$. Materiał rodzimy posiada twardość w zakresie od 161 do 164 HV 5 (rys. 3 i 4). 


\section{WNIOSKI}

1. Dobrane optymalne parametry spawania elektronowego blach z tytanu technicznego Grade 2 to napięcie anodowe $U_{a}=70 \mathrm{kV}$, prąd wiązki $\mathrm{I}_{\mathrm{a}}=8,3 \mathrm{~mA}$, prąd ogniskowania $\mathrm{I}_{\mathrm{o}}=13,8 \mathrm{~A}$, prędkość spawania $\mathrm{V}_{\mathrm{s}}=90 \mathrm{~cm} / \mathrm{min}$.

2. Optymalne parametry spawania metodą TIG blach z tytanu technicznego Grade 2 to natężenie prądu $\mathrm{I}=130 \mathrm{~A}$, napięcia łuku $\mathrm{U}=12 \mathrm{~V}$, prędkość spawania $30 \mathrm{~cm} / \mathrm{min}$, wydatek gazu od strony lica i grani $18 \mathrm{l} / \mathrm{min}$.

3. Wzrost twardości spoiny i strefy wpływu ciepła $\mathrm{w}$ porównaniu $\mathrm{z}$ materiałem rodzimym związany jest głównie ze wzrostem ilości struktury iglastej (fazy $\alpha$ ').

4. Złącza spawane elektronowo charakteryzują się lepszymi własnościami wytrzymałościowymi w stosunku do połączeń spawanych metodą TIG. Związane to jest z mniejszą szerokością SWC i spoiny oraz z mniejszą wielkością ziaren fazy $\alpha$ i igieł fazy $\alpha^{\prime}$ w tych strefach.

5. Zastosowanie lepszej ochrony lica (palnika ze specjalną końcówką) podczas spawania metodą TIG pozwoliłoby uniknąć występowania pęcherzy gazowych i prawdopodobnie wpłynęło na wzrost wytrzymałości złącza spawanego.

\section{LITERATURA}

1. Błaszczyk W., Melechow R., Tubielewicz K.: Tytan i jego stopy. Wydawnictwo Politechniki Częstochowskiej, Częstochowa, 2004.

2. Adamiec P. Szczok E.: Problemy przy spawaniu tytanu i jego stopów. Zeszyty Naukowe Politechniki Opolskiej. Mechanika. Nr 250/99, Z.58, 43-54.

3. Jastrzębski T.: Stopy tytanu w konstrukcjach oceanotechnicznych. Zeszyty Naukowe Politechniki Opolskiej. Mechanika. Nr 250/99, Z.58, 43-54.

4. Welding Titanium a Designers and Users Handbook. The Titanium Information Group. 1999.

5. PN-EN 10002-1:2004. Metale. Próba rozciagania. Część 1: Metodyka badań w temperaturze otoczenia.

6. PN-EN 1321:2000. Spawalnictwo. Badania nieniszczące metalowych złączy spawanych. Badania makroskopowe i mikroskopowe złączy spawanych Badania niszczące spawanych złączy metali. Próba rozciągania próbek poprzecznych.

7. PN-EN 895:1997 Badania niszczące spawanych złączy metali. Próba rozciagania próbek poprzecznych.

8. PN-EN 1043-1:2000. Spawalnictwo. Badania nieniszczące metalowych złączy spawanych. Próba twardości. Próba twardości złączy spawanych łukowo. 